\title{
Study of effect of intra-umbilical oxytocin along with active management in third stage of labor
}

\section{Neetu Verma*, Monica Soni, Priyanka Singh}

Department of Obstetrics and Gynecology, Sardar Patel Medical College and Associated Group of Hospitals, Bikaner, Rajasthan, India

Received: 26 June 2021

Accepted: 26 July 2021

\section{*Correspondence:}

Dr. Neetu Verma,

E-mail: vneetu899@gmail.com

Copyright: (c) the author(s), publisher and licensee Medip Academy. This is an open-access article distributed under the terms of the Creative Commons Attribution Non-Commercial License, which permits unrestricted non-commercial use, distribution, and reproduction in any medium, provided the original work is properly cited.

\section{ABSTRACT}

Background: The aim of the study was to determine effect of intra-umbilical oxytocin along with active management on duration and amount of blood loss in $3^{\text {rd }}$ of stage of labor.

Methods: This was a hospital based prospective, randomized, case-control study conducted in the department of OBG between $1^{\text {st }}$ September 2019 to $31^{\text {st }}$ December 2020. After obtaining permission from ethical committee, screening of inclusion and exclusion criteria and informed consent of participants, 300 cases were enrolled. In group A (control) 20 $\mathrm{ml}$ normal saline and in group B (case) $20 \mathrm{IU}$ oxytocin diluted in normal saline to make a $20 \mathrm{ml}$ solution was given intra-umbilically along with standard active management of third stage labor. The data was systematically recorded and analysed.

Results: Both the groups were comparable in terms of demographic data. A statistically significant reduction in the duration of third stage of labor $(1.83 \pm 0.64 \mathrm{~min}$ in group B vs $2.92 \pm 0.79 \mathrm{~min}$ in group A), amount of blood loss $(203.73 \pm 62.11 \mathrm{ml}$ in group B vs $328.83 \pm 87.18 \mathrm{ml}$ group A) and fall in haemoglobin $(9.28 \pm 1.03 \mathrm{~g} / \mathrm{dl}$ in the study group A vs $9.97 \pm 1.28 \mathrm{~g} / \mathrm{dl}$ in group B) and haematocrit $(31.20 \pm 3.05 \%$ in study group A vs $33.60 \pm 3.31 \%$ in study group B) were noted, taking $\mathrm{p}$ value significant $<0.05$.

Conclusions: Intra-umbilical oxytocin was associated with a significant reduction in duration and amount blood loss in third stage of labor.

Keywords: Intra-umbilical, Oxytocin, Third stage of labor, Active management

\section{INTRODUCTION}

The third stage of labor begins immediately after fetal delivery and involves separation and expulsion of the placenta and membranes. This is the unforgiving stage of labor where a normal case can become abnormal within a minute and successful delivery can turn into an emergency. The average duration reported is $8 \mathrm{~min}$ with a range of 5-15 min. ${ }^{1-3}$ The average blood loss with normal delivery is approximately $370-400 \mathrm{ml}$. The most common complication accompanying this stage is post-partum hemorrhage (PPH).

PPH is one of the most common causes of maternal death throughout the world. Retained placenta is another complication of third stage of labour which occurs in 0.1 to $2 \%$ deliveries and is associated with high risk of hemorrhage. Prevention of postpartum hemorrhage depends on proper management of second stage and third stage of labor.

Active management can prevent $60-70 \%$ of atonic $\mathrm{PPH}$. So active management of third stage of labor has become the rule, to prevent maternal morbidity and mortality. Active management of third stage of labor is a recommended series of steps, including the provision of uterotonic drug immediately upon fetal delivery, controlled cord traction, and uterine tone assessment as developed by the WHO. Oxytocin is the current drug of choice for prevention of PPH. The main advantages are 
rapid onset of action and the lack of side effects such as elevated blood pressure or tetanic contractions. Earlier intra umbilical vein oxytocin injection was used to treat retained placenta. Using this information, some authors have suggested this technique as a measure to reduce the length of third stage of labour and amount of post-partum blood loss. Intra umbilical injected oxytocin reaches the placental bed at relatively higher concentration, causing myometrial contraction thus decreasing the placental attachment site decreasing the blood loss. ${ }^{4}$

The aim of the study was to determine effect of intraumbilical injection of oxytocin along with active management of labor to shorten the duration of the third stage of labor and reduce blood loss in uncomplicated pregnancies.

\section{METHODS}

This study was conducted in the department of Obstetrics and Gynaecology, S. P. Medical College and associated group of hospitals, Bikaner, Rajasthan.

\section{Study design}

The study design was prospective randomized control hospital-based study.

\section{Study place}

The study was carried out at department of obstetrics and gynaecology, PBM Hospital, Bikaner

\section{Study duration}

The study duration was $1^{\text {st }}$ September 2019 to $31^{\text {st }}$ December 2020.

\section{Study sample}

The study sample includes primigravidae with singleton live term fetus with cephalic presentation who underwent normal vaginal delivery of the fetus in the labor room of obstetrics and gynaecology, S.P. medical college and associated group of hospitals, Bikaner, Rajasthan. After ethical committee approval 300 cases were enrolled in the study after screening for the inclusion and exclusion criteria, proper counselling and written informed consent.

\section{Sampling technique}

Sampling technique was simple random sampling method.

\section{Inclusion criteria}

Patients with following criteria were included women willing to participate; primigravidae with singleton live term pregnancy ( 37 to 42 weeks) with cephalic presentation delivered vaginally; spontaneous onset of labor with uneventful $1^{\text {st }}$ and $2^{\text {nd }}$ stage of labor.

\section{Exclusion criteria}

Patients with following criteria were excluded medical or surgical disorders associated with pregnancy; antepartum hemorrhage; malpresentation; multiple pregnancy; hydramnios; chorioamnionitis; severe anemia; Rh negative pregnancy; induced labor; multigravidae; forceps or ventouse application during delivery; previous caesarean section; contraindication to oxytocin; and known hypersensitivity to oxytocin

After obtaining permission from ethical committee, screening of inclusion and exclusion criteria and informed consent of participant, cases were provisionally enrolled in the study. Relevant information related to study subject's socio demographic details, clinical profile, biochemical parameters was collected and recorded. Detailed history of all participants was taken. Clinical examination was done and her hemoglobin and hematocrit values measured. The progress of the labor was monitored. If she had a satisfactory progress of labor and uncomplicated $1^{\text {st }}$ and $2^{\text {nd }}$ stage of labor then she was enrolled for the study. The participants were randomly allocated to any of the 2 groups.

All women received an intramuscular injection of $10 \mathrm{IU}$ of oxytocin at the delivery of the anterior shoulder of the baby as per WHO protocol. Along with intramuscular oxytocin, the cases received intra-umbilical injection of oxytocin or normal saline as per her allocation in group A and group B.

\section{Group A (control)}

$20 \mathrm{ml}$ normal saline was given.

\section{Group B (case)}

$20 \mathrm{IU}$ oxytocin diluted in normal saline to make a $20 \mathrm{ml}$ solution. Each solution was administered intra-umbilically just after the delivery of the baby and cord clamping. The cord was clamped $1 \mathrm{~cm}$ from the introitus and cut, followed by intra-umbilical injection of respective solution in both groups. After the injection was done, another clamp was placed just proximal to the puncture site to prevent leakage of injected fluid.

The cases were then observed for the signs of placental separation. Once signs of placental separation were observed the placenta was delivered by controlled cord traction and placenta and membranes were examined for the completeness after expulsion. The duration of third stage of labor was recorded by stopwatch and noted. The amount of blood loss was quantitatively measured in a calibrated under buttock drape by subtracting the preplacental fluid volume from the post placental fluid volume in the drape. The volume measured by weighing soaked items and blood clots was added to determine the cumulative blood loss, considering $1 \mathrm{~g}$ equal to $1 \mathrm{ml}$ of blood. Blood loss of more than $500 \mathrm{ml}$ was recorded as 
post-partum hemorrhage and managed as per standard protocols. The amount of blood loss, duration of the third stage of labor, third stage complications like PPH and retained placenta need for additional oxytocics were noted. Adverse reaction, if any were also observed recorded and managed as per standard protocol. Patients were observed for two hours following delivery for vitals signs and bleeding per vagina. The maternal hemoglobin and hematocrit values was observed again after 24 hours delivery. The two groups were compared in terms of the duration of the third stage of labor, post-delivery fall in haemoglobin and haematocrit mean difference in $\mathrm{Hb}$ and HCT level, manual delivery of placenta, occurrence of PPH and adverse effects of drugs.

All data collected was entered into Microsoft excel and was analysed with help of appropriate software and tests of significance considering level of significance as $\mathrm{p}<0.05$.

\section{RESULTS}

The mean age of the cases was $22.96 \pm 3.66$ years in the study group A and $23.38 \pm 4.20$ years in group B. Both the study groups were comparable in terms of age. The percentage of booked cases was $57.33 \%$ and $52.66 \%$ in study group A and group B respectively. Both the study groups were comparable to each other with a $p$ value of
0.486 . The mean weight of the new borns was $2.84 \pm 0.32$ $\mathrm{kg}$ in the study group A and $2.78 \pm 0.33 \mathrm{~kg}$ in group B and the difference was statistically insignificant $(p>0.05)$. The mean duration of third stage of labor was $2.92 \pm 0.79$ minutein the study group A and $1.83 \pm 0.64$ min in group B and the difference was statistically significant $(\mathrm{p}<0.05)$.

The mean blood loss during third stage was $328.83 \pm 87.18$ mlin the study group A and $203.73 \pm 62.11 \mathrm{ml}$ in group B and the difference was statistically significant $(\mathrm{p}<0.05)$. The mean fall or difference in pre delivery and postdelivery haemoglobin level was $1.84 \pm 0.59 \mathrm{~g} / \mathrm{dl}$ (range from 0.8 to $3.6 \mathrm{~g} / \mathrm{dl}$ ) in the study group $\mathrm{A}$ and $1.10 \pm 0.50$ $\mathrm{g} / \mathrm{dl}$ (range from 0.4 to $2.6 \mathrm{~g} / \mathrm{dl}$ ) in group B and the difference was statistically significant $(\mathrm{p}<0.05)$. The mean fall or difference in pre delivery and post-delivery haematocrit value was $6.41 \pm 1.84 \%$ (range from 2.2 to 9.4 ) in the study group A and $3.72 \pm 1.38 \%$ (range from 0.6 to 5.2 ) in group $B$ and the difference was statistically significant $(\mathrm{p}<0.05)$.

$\mathrm{PPH}$ in group A is $3.33 \%$ whereas $1.33 \%$ in group B. The incidence of third stage complication was statistically insignificant $(\mathrm{p}>0.05)$. There was no major systemic side effect in both the groups. Mild systemic side effect like nausea and vomiting were noted and managed symptomatically.

Table 1: Distribution of cases according to general variable.

\begin{tabular}{|lll|l|}
\hline Variables & Group A & Group B & P value \\
\hline Age (years) & $22.96 \pm 3.66$ & $23.38 \pm 4.20$ & 0.356 \\
\hline Booked: unbooked & $86: 64$ & $79: 71$ & 0.486 \\
\hline Birth weight (kg) & $2.84 \pm 0.32$ & $2.78 \pm 0.33$ & 0.084 \\
\hline Duration of third stage (min) & $2.92 \pm 0.79$ & $1.83 \pm 0.64$ & 0.0001 \\
\hline Amount of blood loss (ml) & $328.83 \pm 87.18$ & $203.73 \pm 62.11$ & 0.0001 \\
\hline $\begin{array}{l}\text { Fall or difference in pre-delivery and post-delivery } \\
\text { haemoglobin level (g/dl) }\end{array}$ & $1.84 \pm 0.59$ & $1.10 \pm 0.50$ & 0.0001 \\
\hline Difference in pre-delivery and post- delivery haematocrit (\%) & $6.41 \pm 1.84$ & $3.72 \pm 1.38$ & 0.0001 \\
\hline
\end{tabular}

Table 2: Distribution of cases according incidence of third stage complications.

\begin{tabular}{|l|l|l|l|}
\hline Third stage complications & Group A [N (\%)] & Group B [N (\%)] & P value \\
\hline Retained placenta & 0 & 0 & - \\
\hline PPH & $5(3.33)$ & $2(1.33)$ & 0.444 \\
\hline
\end{tabular}

Table 3: Distribution of cases according to their systemic side effects.

\begin{tabular}{|lll|l|}
\hline Systemic side effects & Group A [N (\%)] & Group B [N (\%)] & P value \\
\hline Present & $15(10)$ & $10(6.6)$ & 0.403 \\
\hline Absent & $135(90)$ & $140(93.33)$ & $150(100)$
\end{tabular}

\section{DISCUSSION}

The present study was done to determine the effect of intra-umbilical oxytocin along with active management in third stage of labor. The contribution of every component of AMTSL is important but the use of uterotonics definitely seems to be the most important factor. In a dedicated, maternity unit active management with timely use of uterotonics in optimal dose and route of administration can significantly reduce the amount of blood loss, span of third stage of labor and other third stage complications, thereby reducing the incidence of PPH which is the leading cause if maternal mortality worldwide. Various uterotonics have been used for 
managing third stage of labor. Administration of intra umbilical oxytocin has been proposed as a simple, safe and effective method for active management of third stage of labor.

The results of our study showed that intra-umblical oxytocin along with active management in third stage of labor was effective at reducing the amount of blood loss and duration of $3^{\text {rd }}$ stage labor and hemoglobin and hematocrit values before and after delivery followed the same pattern.

Many studies have agreed with our studies and have cited that the effect of intra umbilical oxytocin on the duration of third stage labor indicating a positive effect in reducing the time for delivery of placenta in third stage. ${ }^{5-7}$

In our study both groups were comparable with regard to demographic data. Compared with group A (control) in which $20 \mathrm{ml}$ of normal saline administered intraumblically a significant reduction in duration of third stage of labor, was noted in group B (cases) where 20 IU of oxytocin diluted in normal saline to make a $20 \mathrm{ml}$ solution i.e. $2.92 \pm 0.29 \mathrm{~min}$ in control vs $1.83 \pm 0.64 \mathrm{~min}$ in cases.

The mean estimated blood loss was significantly lower in cases treated with oxytocin intra-umbilically compared with control group. The mean blood loss was $328.83 \pm 87.18 \mathrm{ml}$ in group A compared to $203.73 \pm 62.11$ $\mathrm{ml}$ in group B. ${ }^{12}$

On comparing the post delivery and pre-delivery hemoglobin level a fall in $\mathrm{Hb}$ level was observed in the women of both groups. The mean hemoglobin level after delivery was $9.28 \pm 1.03 \mathrm{~g} / \mathrm{dl}$ in group A whereas it was $9.97 \pm 1.28 \mathrm{~g} / \mathrm{dl}$ in group $\mathrm{B}$ and the difference was statistically significant $(\mathrm{p}<0.05)$. This indicates a positive association between use of intra-umbilical oxytocin and reduction in blood loss. The hematocrit follows the same pattern and post-delivery hematocrit was $31.60 \pm 3.05 \%$ in group A as compared to $33.60 \pm 3.31 \%$ in group B and the differences was statistically significant.

Several studies used varying values of saline in which oxytocin was diluted and injected intra-umblically for the active management of $3^{\text {rd }}$ stage labor. Intra-umblical administration of oxytocin facilitates the hydrostatic dissection at the placenta surface and leads to the delivery of high concentration of oxytocin at the placenta bed and uterine wall, resulting in myometrial contraction and further separation of placenta. ${ }^{8}$

As observed in the present study an intra umbilical injection of $20 \mathrm{IU}$ of saline diluted to make a $20 \mathrm{ml}$ solution is an effective, safe and non-invasive method for active management in $3^{\text {rd }}$ stage labor.

\section{CONCLUSION}

Intra-umbilical vein administration of oxytocin is an effective and safe method of reducing the duration and amount of blood loss in the third stage of labor. This can be especially promising in countries like India with high prevalence of anemia in an effort to reduce $\mathrm{PPH}$ and thereby reducing maternal mortality and morbidity. However, large multicentric randomized trials are needed to confirm these findings and make recommendations.

\section{Funding: No funding sources \\ Conflict of interest: None declared}

Ethical approval: The study was approved by the Institutional Ethics Committee

\section{REFERENCES}

1. Gulmezoglu AM, Villar J, Ngoc NT, Piaggio G, Carroli G, Adetoro L, et al. WHO multicentre randomised trial of misoprostol in the management of the third stage of labour. Lancet. 2001;358(9283):68995.

2. Dombrowski MP, Bottoms SF, Saleh AA, Hurd WW, Romero R. Third stage of labor: analysis of duration and clinical practice. Am J Obstet Gynecol. 1995;172(4):1279-84.

3. Paine LL. Obstetrics: Normal and Problem Pregnancies. New York, NY: Churchill Livingstone; 1988: 290-291.

4. Gungorduk K, Asicioglu O, Besimoglu B, Gungorduk OC, Yildirm G, Ark C, et al. Using intraumbilical vein injection of oxytocin in routine practice with active management of the third stage of labor: a randomized controlled trial. Obstet Gynecol. 2010;116(3):619-24.

5. Dahiya P, Puri M, Rathee S. Influence of intraumbilical oxytocin on the third stage of labour. Indian J Med Sci. 1995;49(2):23-7.

6. Kovavisarach E, Rojsangruang S. Effect of umbilical vein oxytocin injection on the third stage of labor: a randomized controlled study. J Med Assoc Thai. 1998;81(9):693-7.

7. Sawai D, Sharma SK, Jain G. Effect of different doses of intraumbilical oxytocin on third stage of labor. J South Asian Feder Obstet Gynacol. 2016;8(4):286-9.

8. Brant HA. Precise estimation of PPH: difficulties and importance. Br Med J. 1967;1(5537):398-400.

Cite this article as: Verma N, Soni M, Singh P. Study of effect of intra-umbilical oxytocin along with active management in third stage of labor. Int $\mathbf{J}$ Reprod Contracept Obstet Gynecol 2021;10:3486-9. 